\title{
Die Lesung
}

Erhard Taverna
Eine Herbstlese an der Limmat. Regenböen schütteln Schirme, es riecht nach Schnee. Pünktlich zur Eröffnung im Debattiersaal des Literaturhauses bricht die Sonne durch. Im Rücken des Publikums liegen in Glasvitrinen die aufgeschlagenen Bücher schreibender Frauen des 19. Jahrhunderts. Die Werke sind Teil einer ergänzenden, kleinen Ausstellung zu Autorinnen von Karoline Günderrode bis Marlen Haushofer, die im Museum Strauhof als «Gruppenbild mit Damen» auftreten.

Heute tritt dort eine Herrenrunde auf, genauer ein Medizinerquartett. Jan Fischer liest aus seiner Autobiographie «Der Calcium-Fischer», Hansruedi Gehring aus seinem Buch «Termiten an Bord», Andreas Köhler aus dem Manuskript «Neyers Weg zum Sacromonte» und Kaspar Wolfensberger aus dem noch unveröffentlichten Roman «Der Seelenwexler». Allen Erzählfiguren gemeinsam ist der lange Weg einer Selbstfindung. Immer geht es um die Frage nach einem gelungenen Leben, um Glück und Heilung oder das Gegenteil. Die Texte eröffnen eine Bühne, die fiktiv oder eigenem Erleben folgend, ein weites Panorama von Glück und Unglück eröffnen. Der eine findet den Geschmack am Leben im wissenschaftlichen Forschen und lebenslänglichen Sammeln von Kunstobjekten, ein anderer ermittelt in klassischer Krimimanier auf einem Ozeandampfer, wobei wir nebenbei erfahren, was es

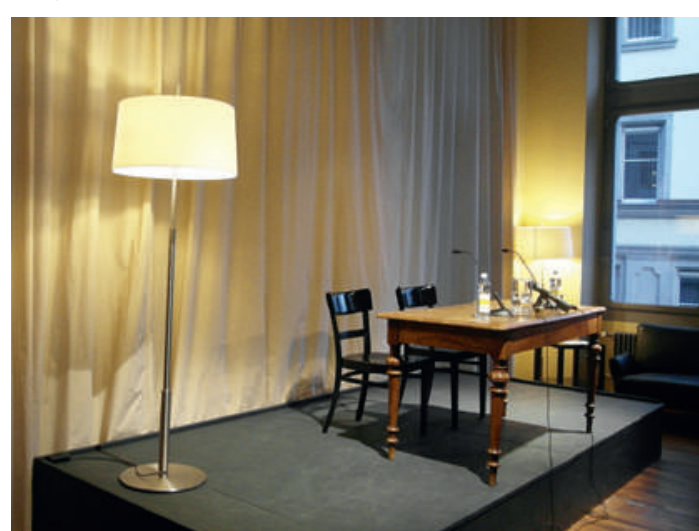

Tatort sucht weitere Autorinnen und Autoren. (Archiv Literaturhaus) tig - sich im Schreiben eine zusätzliche Welt erschlossen haben. Wer die Sprache zum wichtigsten Werkzeug macht, wird vermutlich Psychiater. Von dieser Spezies kamen an diesem Abend gleich drei zu Wort. Zufällig oder nicht, ob diese häufiger literarisch in Erscheinung treten als Kollegen anderer Fächer, war eine Frage, die sich nicht schlüssig beantworten liess. Zuhörerinnen und Zuhörer erkundigten sich nach der Praxis des Autorenmetiers, nach dem Aufwand und Vorgehen, nach den Mühsalen der Verlagsfindung und den neuen Publikationsmöglichkeiten wie E-Book. Die lebhaften Gespräche fanden beim Apéro riche und dem Büchertisch eine Fortsetzung.

Im Literaturhaus, einer Einrichtung der Museumsgesellschaft in Zusammenarbeit mit der Stadt Zürich, lesen jährlich auch Ärztinnen und Ärzte aus ihren Werken. Organisiert werden die Abende vom Geschäftsführer der Alumni-Organisation der medizinischen Fakultät. Ein Besuch lohnt sich auf jeden Fall, denn im gleichen Haus sind auch eine Bibliothek und ein Lesesaal der Gesellschaft untergebracht. Ein Ort der Ruhe mit Blick auf Altstadt und Fluss, reichlich ausgestattet mit Periodika, Zeitungen und einem reichen Fundus an neuen und alten Büchern. Ein abwechslungsreiches Monatsprogramm bietet Vernissagen und Autorenlesungen, Buchsafaris für Kinder und Auftritte im Theater mit Reticulotermes lucifugus auf sich hat. Ein fleissiger Spitalarzt springt über eine Brücke und begibt sich als Überlebender auf eine mühselige und zauberhafte Wallfahrt, dreissig lange Etappen, um sich selbst zu finden. Die vorgetragene Szene eines raffinierten inneren Monologs des in eine Klosterfrau verliebten Protagonisten unterhielt mit einer beachtlichen schauspielerischen Leistung. Den Abschluss machte ein psychiatrischer Schelmenroman, vom Autor mit sichtlichem Vergnügen vorgetragen, worin ein schlitzohriger Hochstapler als Praxisstellvertreter alles in die Tat umsetzt, was ein seriöser Arzt nicht einmal denken darf. Wer wollte nicht auch einmal Gion-Gieri Caduff alias Phil Wexler sein? Ein Gaunerstück, das viel Aufmerksamkeit fand.

Es war eine ausgezeichnete Gelegenheit, Kollegen kennenzulernen, die - in der Mehrzahl berufstä-
Rigiblick. Ab dem Hauptbahnhof ist die Adresse am Limmatquai 62 bequem mit dem Tram Nr. 4 bis Haltestelle Rathaus zu erreichen. Weitere Auskünfte über geplante Lesungen erteilt der Organisator Dr. med. H. R. Gonzenbach über die Website der Fakultät oder per Mail: www.medalumni.uzh.ch / med[at] alumni.uzh.ch

\section{Erwähnte Literatur}

- Fischer J. Der Calcium-Fischer - Wie wird so einer Kunstsammler? Zürich: Elster Verlag; 2013.

- Gehring H. Termiten an Bord. Zürich: Wolfbach Verlag; 2010.

- Köhler A. Neyers Weg zum Sacromonte, noch unveröffentlicht.

- Wolfensberger K. Der Seelenwexler. Publikation vorgesehen Ende 2013. 